

Leandro Fontoura Cupertino

\title{
Modelagem do módulo de Young em nanocompósitos através de Inteligểncia \\ Computacional
}

Dissertação de Mestrado

Dissertação apresentada como requisito parcial para obtenção do grau de Mestre pelo Programa de Pós-graduação em Engenharia Elétrica do Departamento de Engenharia Elétrica da PUC-Rio

Orientador : Prof. Marco Aurélio Cavalcanti Pacheco Co-Orientador: Prof. José Roberto Moraes d'Almeida 


\title{
Leandro Fontoura Cupertino
}

\author{
Modelagem do módulo de Young em \\ nanocompósitos através de Inteligência \\ Computacional
}

Dissertação apresentada como requisito parcial para obtenção do grau de Mestre pelo Programa de Pós-graduação em Engenharia Elétrica do Departamento de Engenharia Elétrica do Centro Técnico Científico da PUC-Rio. Aprovada pela Comissão Examinadora abaixo assinada.

Prof. Marco Aurélio Cavalcanti Pacheco Orientador Departamento de Engenharia Elétrica - PUC-Rio

Prof. José Roberto Moraes d'Almeida Co-Orientador Departamento de Ciência dos Materiais e Metalurgia PUC-Rio

Prof. Evaristo Chalbaud Biscaia Junior Programa de Engenharia Química — UFRJ

Prof. Flávia Cassiola

Petrobrás

Prof. Marley M. B. R. Vellasco Departamento de Engenharia Elétrica - PUC-Rio

Prof. José Eugênio Leal Coordenador Setorial do Centro Técnico Científico - PUC-Rio 
Todos os direitos reservados. É proibida a reprodução total ou parcial do trabalho sem autorização da universidade, do autor e do orientador.

\section{Leandro Fontoura Cupertino}

Graduou-se em Engenharia Elétrica na Universidade do Estado do Rio de Janeiro.

Ficha Catalográfica

Cupertino, Leandro Fontoura

Modelagem do módulo de Young em nanocompósitos através de Inteligência Computacional / Leandro Fontoura Cupertino; orientador: Marco Aurélio Cavalcanti Pacheco; coorientador: José Roberto Moraes d'Almeida. - 2009.

82 f.: il.(color.) ; $30 \mathrm{~cm}$

Dissertação (Mestrado em Engenharia Elétrica) - Pontifícia Universidade Católica do Rio de Janeiro, Rio de Janeiro, 2009.

Inclui bibliografia.

1. Engenharia Elétrica - Teses. 2. Nanocompósitos. 3. Módulo de Young. 4. Redes neurais artificiais. 5. Algoritmos genéticos. I. Pacheco, Marco Aurélio Cavalcanti. II. d'Almeida, José Roberto Moraes. III. Pontifícia Universidade Católica do Rio de Janeiro. Departamento de Engenharia Elétrica. IV. Título. 


\section{Agradecimentos}

Aos meus pais pelos conselhos e constante incentivo ao estudo durante toda minha vida.

À minha namorada Nicole pelo amor, paciência e ajuda nas revisões.

Aos meus orientadores professores Marco Aurélio Pacheco e José Roberto d'Almeida pelo estímulo e parceria na realização desse trabalho.

Aos amigos Omar Paranaíba, Anderson Singulani e Iury Steiner, pelo apoio e pelas discussões sobre o tema.

Aos meus amigos e colegas da PUC-Rio, do ICA e da UERJ que sempre me apoiaram.

Ao CNPq e à PUC-Rio, pelos auxílios concedidos, sem os quais este trabalho não poderia ter sido realizado. 


\section{Resumo}

Cupertino, Leandro Fontoura; Pacheco, Marco Aurélio Cavalcanti; d'Almeida, José Roberto Moraes. Modelagem do módulo de Young em nanocompósitos através de Inteligência Computacional. Rio de Janeiro, 2009. 82p. Dissertação de Mestrado

- Departamento de Engenharia Elétrica, Pontifícia Universidade Católica do Rio de Janeiro.

Materiais compósitos são a base de muitos produtos, devido à sua capacidade de aperfeiçoar certas propriedades. Recentemente, a utilização de nanocargas na fabricação de compósitos vem sendo amplamente estudada, pois a partir de concentrações baixas de nanocargas, as propriedades começam a melhorar, possibilitando a criação de materiais leves e com uma grande gama de propriedades. Uma das propriedades mecânicas mais estudadas é o módulo de Young, que mensura a rigidez de um material. Alguns dos modelos existentes para essa propriedade em nanocompósitos pecam na precisão ou são limitados em função da fração máxima de nanopartículas admissível no modelo. Outros se adéquam apenas a uma determinada combinação de matriz/carga preestabelecida. O objetivo deste trabalho é utilizar Redes Neurais Artificiais como um aproximador capaz de modelar tal propriedade para diversas matrizes/cargas, levando em consideração suas características, sem perder a precisão. A validação do aproximador é realizada comparando o resultado com outros modelos propostos na literatura. Uma vez validada, utiliza-se Algoritmos Genéticos em conjunto com tal rede para definir qual seria a configuração ideal para três casos de estudo: um que maximize o valor do módulo de Young, outro que maximize o módulo relativo e um terceiro que maximize o módulo relativo e minimize a quantidade de carga utilizada, diminuindo os custos de projeto. As técnicas de Inteligência Computacional empregadas na modelagem e síntese de materiais nanoestruturados se mostraram boas ferramentas, uma vez que geraram uma boa aproximação dos dados utilizados com erros inferiores a $5 \%$, além de possibilitarem a determinação dos parâmetros de síntese de um material com o módulo de Young desejado.

\section{Palavras-chave}

Nanocompósitos; módulo de Young; redes neurais artificiais; algoritmos genéticos. 


\section{Abstract}

Cupertino, Leandro Fontoura; Pacheco, Marco Aurélio Cavalcanti (Advisor); d'Almeida, José Roberto Moraes. Modeling Young's modulus of nanocomposites through Computational Intelligence. Rio de Janeiro, 2009. 82p. MSc Dissertation - Departamento de Engenharia Elétrica, Pontifícia Universidade Católica do Rio de Janeiro.

Composite materials became very popular due to its improvements on certain properties achieved from the mixture of two different components. Recently, the use of nanofillers in the manufacture of composites has been widely studied due to the improvement of properties at low concentrations of nanofillers, enabling the creation of lightweight materials. Some of the existing models for the Young modulus of the nanocomposites have low accuracy or are limited in terms of the maximum filler fraction possible. Others are appropriate only for a given combination of matrix and filler. The objective of this work is to use Artificial Neural Networks as a function approximation method capable of modeling such property for various matrix/nanofillers, taking into account their characteristics, without losing accuracy. The validation of this approximator is performed comparing its results with other models proposed in the literature. Once validated, a Genetic Algorithm is used with the Neural Network to define which would be the ideal setting for three case studies: one that maximizes the value of composite's Young's modulus, other that maximizes the relative modulus and a third one that maximizes the relative modulus and minimizes the amount of load used, reducing the cost of project. Computational Intelligence techniques employed on the modeling and synthesis of nanostructured materials proved to be adequate tools, since it generated a good approximation of the data with errors lower than $5 \%$, and determined the material's parameters for synthesis with the desired Young's modulus.

\section{Keywords}

Nanocomposites; Young's modulus; artificial neural networks; genetic algorithms. 


\section{Sumário}

1 Introdução $\quad 15$

$\begin{array}{lll}1.1 & \text { Motivação } & 17\end{array}$

$\begin{array}{lll}1.2 & \text { Objetivos } & 18\end{array}$

$\begin{array}{lll}1.3 & \text { Organização do Trabalho } & 18\end{array}$

2 Materiais Compósitos 20

2.1 Nanocompósitos 21

2.2 Matrizes 22

2.3 Partículas 23

2.3.1 Esféricas 24

2.3.2 Baculiformes 24

$\begin{array}{lll}2.3 .3 & \text { Lamelares } & 25\end{array}$

2.4 Propriedades beneficiadas 26

2.5 Modelagem do Módulo de Young 28

$\begin{array}{lll}2.5 .1 & \text { Regra das misturas } & 29\end{array}$

2.5.2 Modelos empíricos 30

3 Inteligência Computacional $\quad 32$

3.1 Redes Neurais 32

3.1.1 Histórico 33

$\begin{array}{ll}\text { 3.1.2 Estrutura de uma Rede } & 34\end{array}$

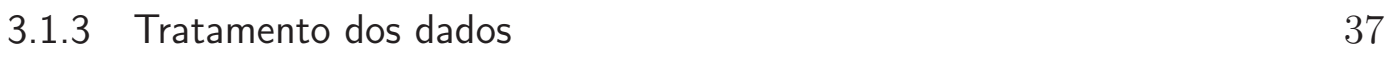

$\begin{array}{lll}3.1 .4 & \text { Treinamento } & 38\end{array}$

3.2 Algoritmos Genéticos 43

3.2.1 Representações $\quad 45$

$\begin{array}{ll}3.2 .2 \text { Operadores } & 46\end{array}$

3.2.3 Múltiplos objetivos $\quad 47$

4 Modelagem e síntese de materiais assistida por IC 49

4.1 Modelagem do módulo de Young por redes neurais 49

4.1.1 Aquisição e análise dos dados $\quad 50$

4.1.2 Tratamento dos dados $\quad 52$

4.1.3 Configuração dos experimentos 54

4.2 Comparação entre modelos $\quad 55$

4.3 Síntese de Materiais por Algoritmos Genéticos 55

$\begin{array}{lll}5 & \text { Resultados } & 57\end{array}$

5.1 Redes Neurais $\quad 57$

5.1.1 Tratamento dos dados $\quad 57$

$\begin{array}{lll}\text { 5.1.2 Escolha da melhor RNA } & 58\end{array}$

5.1.3 Comportamento dos nanocompósitos 64

5.2 Comparação entre modelos 67

5.3 Algoritmo Genético 68 
6 Conclusão e trabalhos futuros

A Dados experimentais 


\section{Lista de figuras}

1.1 Importância relativa dos metais, polímeros, compósitos e cerâmicas em função do tempo.

1.2 Utilização de nanocompósitos na indústria em 2005 e projeção de mercado para 2011. Valores em milhões de dólares.

2.1 Comparação entre materiais monolíticos convencionais e materiais compósitos.

2.2 Arquitetura molecular dos polímeros.

2.3 Estrutura molecular dos nanotubos de carbono: armchair (a), zigzag (b) e chiral (c).

2.4 Estrutura molecular da montmorilonita. 26

2.5 Permeabilidade a gás em polímeros (a) e nanocompósitos (b). $\quad 27$

2.6 Teste de tração em materiais. 27

2.7 Curva tensão por deformação em um material. 28

2.8 Curva tensão-deformação de um compósito de fibra contínua, mostrando como ela está relacionada com as das fibras e da matriz. 29

3.1 Representação gráfica de um neurônio artificial. 34

3.2 Exemplo de uma rede neural não recorrente. 36

3.3 Exemplo de uma rede neural recorrente com duas entradas e duas saídas.

3.4 Treinamento supervisionado de uma rede neural.

3.5 Validação cruzada. Ilustração de dois momentos distintos do treinamento: generalização da rede (a) e supertreinamento (b). 43

3.6 Dependência entre o ponto inicial e o erro final obtido. 44

3.7 Cruzamento de um ponto. 47

4.1 Representação esquemática da RNA desejada. $\quad 50$

4.2 Histograma e o percentual cumulativo de cada uma das característica dos compósitos.

4.3 Representação esquemática da solução do AG. $\quad 56$

5.1 Normalizações referentes à classe e ao módulo de Young da matriz. 58

5.2 Normalização referente à classe da partícula. 58

5.3 Normalização uniforme e por partes da fração mássica da partícula. 59

5.4 Normalização uniforme e por partes do diâmetro da partícula. $\quad 59$

5.5 Normalização uniforme e por partes da razão de aspecto da partícula. 59

5.6 Normalização uniforme e por partes do módulo de Young relativo do compósito.

5.7 Resultados da melhor rede para os conjuntos de treinamento, validação e teste.

5.8 Correlação entre os valores alvo e os obtidos pela melhor rede para cada conjunto.

5.9 Módulo relativo do nanocompósito em função da concentração da carga. 
5.10 Curvas de nível referentes ao $E_{r}$ em função do diâmetro e concentração de $\mathrm{CaCO}_{3}$ em iPP.

5.11 Aplicação dos modelos analíticos e da RNA ao compósito de PA6/Nanoargila.

5.12 Aplicação dos modelos analíticos e da RNA ao compósito de SBR/Nanoargila.

5.13 Aplicação dos modelos analíticos e da RNA ao compósito de NBR/Nanoargila.

5.14 Aplicação dos modelos analíticos e da RNA ao compósito de CNBR/Nanoargila. 


\section{Lista de tabelas}

3.1 Funções de ativação e suas respectivas derivadas. 35

4.1 Polímeros utilizados como matriz no desenvolvimento da rede. $\quad 51$

4.2 Partículas utilizadas como carga no desenvolvimento da rede. $\quad 51$

4.3 Enumeração das matrizes e cargas utilizadas. 53

4.4 Valores utilizados para a normalização linear uniforme e por partes. 54

4.5 Diferenças entre experimentos. 54

4.6 Configuração comum a todos os experimentos. 55

$\begin{array}{ll}\text { 4.7 Diferenças entre conjuntos. } & 56\end{array}$

5.1 Resultados do experimento 1 (classes com normalização linear). $\quad 60$

5.2 Resultados do experimento 2 (classes com normalização por partes). 61

5.3 Resultados do experimento 3 (propriedades intrínsecas com normalização linear). 62

5.4 Resultados do experimento 4 (propriedades intrínsecas com normalização linear). $\quad 62$

5.5 Comparação entre os algoritmos de treinamento 63

5.6 Parâmetros de configuração utilizados na execução do AG. $\quad 70$

5.7 Resultados dos três casos de estudo do AG. $\quad 70$

A.1 Dados retirados de tabelas disponíveis na literatura. 79

A.2 Dados retirados de tabelas disponíveis na literatura. (continuação) 80

A.3 Dados retirados de gráficos disponíveis na literatura. 81

A.4 Dados retirados de gráficos disponíveis na literatura. (continuação) 82 


\section{Sumário de Notações}

\section{Notações Gerais}

$\nu \quad$ Coeficiente de Poisson

$E_{c} \quad$ Módulo do compósito

$E_{d} \quad$ Módulo de Young da fase dispersa

$E_{m} \quad$ Módulo de Young da matriz

$E_{r} \quad$ Módulo de Young relativo

$G \quad$ Módulo de cisalhamento

$K \quad$ Módulo volumétrico

$\mathrm{m}_{d} / \mathrm{m}_{c} \quad$ Fração mássica da fase dispersa

$\mathrm{ID}_{d} \quad$ Identificação da fase dispersa

$\mathrm{ID}_{m} \quad$ Identificação da matriz

$\% \mathrm{~m} / \mathrm{m}$ Percentual mássico

$\% \mathrm{v} / \mathrm{v} \quad$ Percentual volumétrico

AG Algoritmos Genéticos

IC Inteligência Computacional

MAPE Erro percentual médio absoluto

MSE Erro quadrático médio

RNA Redes Neurais Artificiais

SSE Soma dos erros quadráticos

$\mathrm{D}_{d} \quad$ Diâmetro da fase dispersa (carga)

$\mathrm{RA}_{d} \quad$ Razão de aspecto da fase dispersa (carga)

\section{Matrizes}

$\begin{array}{ll}\text { CNBR } & \text { Borracha nitrílica carboxilada } \\ \text { E-glass-PP } & \text { Polipropileno com fibras de vidro } \\ \text { iPP } & \text { Polipropileno isotático } \\ \text { N66 } & \text { Náilon } 66 \\ \text { NBR } & \text { Borracha de nitrilo butadieno } \\ \text { OS } & \text { Poliestireno } \\ \text { PA6 } & \text { Poliamida } 6 \\ \text { PE } & \text { Polietileno } \\ \text { PLLA } & \text { Ácido L-polilático } \\ \text { PMMA } & \text { Polimetilmetacrilato } \\ \text { PP } & \text { Polipropileno } \\ \text { PTFE } & \text { Politetrafluoretileno } \\ \text { PU } & \text { Poliuretano } \\ \text { PVC } & \text { Cloreto de Polivinila } \\ \text { SBR } & \text { Borracha de estireno-butadieno } \\ \text { UP } & \text { Poliéster não saturado }\end{array}$




\section{Cargas}

$\mathrm{CaCO}_{3} \quad$ Carbonato de cálcio

$\mathrm{CB}$

Negro de fumo

CNF Nanofibra de carbono

CNT Nanotubo de carbono

DWCNT Nanotubo de carbono de parede dupla

DWCNT- $\mathrm{NH}_{2} \quad$ Nanotubo de carbono de parede dupla aminofuncionalizado

g-HAP Hidrocarboneto aromático enxertado

HAP Hidrocarboneto aromático

MMT Montmorilonita

MWCNT Nanotubo de carbono de paredes múltiplas

MWCNT-NH $\mathrm{N}_{2} \quad$ Nanotubo de carbono de paredes múltiplas aminofuncionalizado

$\mathrm{SiO}_{2} \quad$ Sílica (dióxido de silício)

SWCNT Nanotubo de carbono de parede única

$\mathrm{TiO}_{2} \quad$ Titânia (dióxido de titânio) 
Size matters not. Look at me. Judge me by my size, do you?

Master Yoda, Star Wars Episode V: The Empire Strikes Back. 